Bull. Korean Math. Soc. 49 (2012), No. 2, pp. 339-352

http://dx.doi.org/10.4134/BKMS.2012.49.2.339

\title{
APPROXIMATELY QUINTIC AND SEXTIC MAPPINGS ON THE PROBABILISTIC NORMED SPACES
}

\author{
Mohammad Bagher Ghaemi, Hamid Majani, and Majid Eshaghi Gordji
}

\begin{abstract}
We prove the stability for the systems of quadratic-cubic and additive-quadratic-cubic functional equations with constant coefficients on the probabilistic normed spaces (briefly PN spaces).
\end{abstract}

\section{Introduction and preliminaries}

The stability of functional equations started with the following question concerning stability of group homomorphisms proposed by S. M. Ulam [80] during a talk before a Mathematical Colloquium at the University of Wisconsin, Madison, in 1940:

Let $\left(G_{1}, \cdot\right)$ be a group and let $\left(G_{2}, *\right)$ be a metric group with the metric $d(\cdot, \cdot)$. Given $\epsilon>0$, does there exist a $\delta>0$, such that if a mapping $h: G_{1} \longrightarrow G_{2}$ satisfies the inequality $d(h(x \cdot y), h(x) * h(y))<\delta$ for all $x, y \in G_{1}$, then there exists a homomorphism $H: G_{1} \longrightarrow G_{2}$ with $d(h(x), H(x))<\epsilon$ for all $x \in G_{1}$ ?

In 1941, Hyers [40] gave a first affirmative answer to the question of Ulam for Banach spaces as follows:

If $E$ and $E^{\prime}$ are Banach spaces and $f: E \longrightarrow E^{\prime}$ is a mapping for which there is $\varepsilon>0$ such that $\|f(x+y)-f(x)-f(y)\| \leq \varepsilon$ for all $x, y \in E$, then there is a unique additive mapping $L: E \longrightarrow E^{\prime}$ such that $\|f(x)-L(x)\| \leq \varepsilon$ for all $x \in E$.

Hyers' Theorem was generalized by Aoki [3] for additive mappings and by Rassias [72] for linear mappings by considering an unbounded Cauchy difference. The paper of Rassias [73] has provided a lot of influence in the development of what we now call generalized Hyers-Ulam stability or as HyersUlam-Rassias stability of functional equations. In 1982-1994, J. M. Rassias (see [64]-[71]) solved the Ulam problem for different mappings and for many Euler-Lagrange type quadratic mappings, by involving a product of different powers of norms. In addition, J. M. Rassias considered the mixed product-sum

Received November 2, 2010.

2010 Mathematics Subject Classification. 39B52, 46S50, 47H10.

Key words and phrases. probabilistic normed spaces, generalized Hyers-Ulam stability, mixed type functional equation. 
of powers of norms control function [75]. In 1994, a generalization of the Rassiastheorem was obtained by Găvruta [37] by replacing the unbounded Cauchy difference by a general control function in the spirit of Rassiasapproach. For more details about the results concerning such problems the reader is referred to $[4,6,7,24,36,41,44,45,46]$ and [58]-[74].

Khodaei and Rassias [49] investigated the solution and stability of the $n$ dimensional additive functional equation such that in the special case $n=2$,

$$
f(a x+b y)+f(a x-b y)=2 a f(x)
$$

for $a, b \in \mathbb{Z} \backslash\{0\}$ with $a \neq \pm 1, \pm b$. The authors proved that additive equation is equivalent to the above equation.

The functional equation

$$
f(x+y)+f(x-y)=2 f(x)+2 f(y)
$$

is related to a symmetric bi-additive function $[1,47]$. It is natural that this equation is called a quadratic functional equation. In particular, every solution of the quadratic equation (1.2) is said to be a quadratic function. It is well known that a function $f$ between real vector spaces is quadratic if and only if there exists a unique symmetric bi-additive function $B_{1}$ such that $f(x)=B_{1}(x, x)$ for all $x$. The bi-additive function $B_{1}$ is given by $B_{1}(x, y)=$ $\frac{1}{4}(f(x+y)-f(x-y))$. The Hyers-Ulam stability problem for the quadratic functional equation was solved by Skof [79]. In [6], Czerwik proved the HyersUlam-Rassias stability of the equation (1.2). Eshaghi Gordji and Khodaei [25] obtained the general solution and the generalized Hyers-Ulam-Rassias stability of the following quadratic functional equation for $a, b \in \mathbb{Z} \backslash\{0\}$ with $a \neq \pm 1, \pm b$,

$$
f(a x+b y)+f(a x-b y)=2 a^{2} f(x)+2 b^{2} f(y) .
$$

Jun and Kim [42] introduced the following cubic functional equation

$$
f(2 x+y)+f(2 x-y)=2 f(x+y)+2 f(x-y)+12 f(x)
$$

and they established the general solution and the generalized Hyers-UlamRassias stability for the functional equation (1.4). They proved that a function $f$ between two real vector spaces $X$ and $Y$ is a solution of (1.4) if and only if there exists a unique function $C: X \times X \times X \longrightarrow Y$ such that $f(x)=$ $C(x, x, x)$ for all $x \in X$, moreover, $C$ is symmetric for each fixed one variable and is additive for fixed two variables. The function $C$ is given by $C(x, y, z)=$ $\frac{1}{24}(f(x+y+z)+f(x-y-z)-f(x+y-z)-f(x-y+z))$ for all $x, y, z \in X$. Obviously, the function $f(x)=c x^{3}$ satisfies the functional equation (1.4), which is called the cubic functional equation. Jun et al. [43] investigated the solution and the Hyers-Ulam stability for the cubic functional equation

(1.5) $f(a x+b y)+f(a x-b y)=a b^{2}(f(x+y)+f(x-y))+2 a\left(a^{2}-b^{2}\right) f(x)$,

where $a, b \in \mathbb{Z} \backslash\{0\}$ with $a \neq \pm 1, \pm b$. For other cubic functional equations see [53]-[57]. Lee et al. [50] considered the following functional equation

$$
f(2 x+y)+f(2 x-y)=4 f(x+y)+4 f(x-y)+24 f(x)-6 f(y) .
$$


In fact, they proved that a function $f$ between two real vector spaces $X$ and $Y$ is a solution of (1.6) if and only if there exists a unique symmetric bi-quadratic function $B_{2}: X \times X \longrightarrow Y$ such that $f(x)=B_{2}(x, x)$ for all $x$. The bi-quadratic function $B_{2}$ is given by $B_{2}(x, y)=\frac{1}{12}(f(x+y)+f(x-y)-2 f(x)-2 f(y))$. Obviously, the function $f(x)=c x^{4}$ satisfies the functional equation (1.6), which is called the quartic functional equation. For more functional equations see [8][35], [5, 38, 39, 48, 51, 52, 59, 78].

Ebadian, Najati and Eshaghi Gordji [9] considered the generalized HyersUlam stability of the systems additive-quartic functional equations

$$
\left\{\begin{aligned}
f\left(x_{1}+x_{2}, y\right)= & f\left(x_{1}, y\right)+f\left(x_{2}, y\right) \\
f\left(x, 2 y_{1}+y_{2}\right)+f\left(x, 2 y_{1}-y_{2}\right)= & 4 f\left(x, y_{1}+y_{2}\right)+4 f\left(x, y_{1}-y_{2}\right) \\
& +24 f\left(x, y_{1}\right)-6 f\left(x, y_{2}\right)
\end{aligned}\right.
$$

and the quadratic-cubic functional equations

$$
\left\{\begin{array}{l}
f\left(x, 2 y_{1}+y_{2}\right)+f\left(x, 2 y_{1}-y_{2}\right)=2 f\left(x, y_{1}+y_{2}\right)+2 f\left(x, y_{1}-y_{2}\right)+12 f\left(x, y_{1}\right) \\
f\left(x, y_{1}+y_{2}\right)+f\left(x, y_{1}-y_{2}\right)=2 f\left(x, y_{1}\right)+2 f\left(x, y_{2}\right)
\end{array}\right.
$$

In this paper, we investigate the stability for the systems of quadratic-cubic functional equations

$$
\left\{\begin{aligned}
f\left(a x_{1}+b x_{2}, y\right)+f\left(a x_{1}-b x_{2}, y\right)= & 2 a^{2} f\left(x_{1}, y\right)+2 b^{2} f\left(x_{2}, y\right) \\
f\left(x, a y_{1}+b y_{2}\right)+f\left(x, a y_{1}-b y_{2}\right)= & a b^{2}\left(f\left(x, y_{1}+y_{2}\right)+f\left(x, y_{1}-y_{2}\right)\right) \\
& +2 a\left(a^{2}-b^{2}\right) f\left(x, y_{1}\right)
\end{aligned}\right.
$$

and additive-quadratic-cubic functional equations

$$
\left\{\begin{aligned}
f\left(a x_{1}+b x_{2}, y, z\right)+f\left(a x_{1}-b x_{2}, y, z\right)= & 2 a f\left(x_{1}, y, z\right) \\
f\left(x, a y_{1}+b y_{2}, z\right)+f\left(x, a y_{1}-b y_{2}, z\right)= & 2 a^{2} f\left(x, y_{1}, z\right)+2 b^{2} f\left(x, y_{2}, z\right) \\
f\left(x, y, a z_{1}+b z_{2}\right)+f\left(x, y, a z_{1}-b z_{2}\right)= & a b^{2}\left(f\left(x, y, z_{1}+z_{2}\right)+f\left(x, y, z_{1}-z_{2}\right)\right) \\
& +2 a\left(a^{2}-b^{2}\right) f\left(x, y, z_{1}\right)
\end{aligned}\right.
$$

where $a, b \in \mathbb{Z} \backslash\{0\}$ with $a \neq \pm 1, \pm b$. The function $f: \mathbb{R} \times \mathbb{R} \rightarrow \mathbb{R}$ given by $f(x, y)=c x^{2} y^{3}$ is a solution of (1.9). In particular, letting $y=x$, we get a quintic function $g: \mathbb{R} \rightarrow \mathbb{R}$ in one variable given by $g(x):=f(x, x)=c x^{5}$. Also, it is easy to see that the function $f: \mathbb{R} \times \mathbb{R} \times \mathbb{R} \rightarrow \mathbb{R}$ defined by $f(x, y, z)=$ $c x y^{2} z^{3}$ is a solution of (1.10). In particular, letting $y=z=x$, we get a sextic function $h: \mathbb{R} \rightarrow \mathbb{R}$ in one variable given by $h(x):=f(x, x, x)=c x^{6}$.

The proof of the following propositions are evident and we omit the details.

Proposition 1.1. Let $X$ and $Y$ be real linear spaces. If a function $f: X \times$ $X \longrightarrow Y$ satisfies (1.9), then $f(\lambda x, \mu y)=\lambda^{2} \mu^{3} f(x, y)$ for all $x, y \in X$, and all rational numbers $\lambda, \mu$. 
Proposition 1.2. Let $X$ and $Y$ be real linear spaces. If a function $f: X \times$ $X \times X \longrightarrow Y$ satisfies (1.10), then $f(\lambda x, \mu y, \eta z)=\lambda \mu^{2} \eta^{3} f(x, y, z)$ for all $x, y, z \in X$, and all rational numbers $\lambda, \mu, \eta$.

PN spaces were first defined by Šerstnev in 1962 (see [77]). Their definition was generalized in [2]. We recall and apply the definition of probabilistic space briefly as given in [76], together with the notation that will be needed (see [76]).

Definition 1.1. A distance distribution function (briefly, a d.d.f.) is a nondecreasing function $F$ from $\overline{\mathbb{R}}^{+}$into $[0,1]$ that satisfies $F(0)=0$ and $F(+\infty)=$ 1 , and is left-continuous on $(0,+\infty)$; here as usual, $\overline{\mathbb{R}}^{+}:=[0,+\infty]$.

The space of d.d.f.'s will be denoted by $\Delta^{+}$; and the set of all $F$ in $\Delta^{+}$for which $\lim _{t \rightarrow+\infty^{-}} F(t)=1$ by $D^{+}$. The space $\Delta^{+}$is partially ordered by the usual pointwise ordering of functions, i.e., $F \leq G$ if and only if $F(x) \leq G(x)$ for all $\mathrm{x}$ in $\overline{\mathbb{R}}^{+}$. For any $a \geq 0, \varepsilon_{a}^{+}$is the d.d.f. given by

$$
\varepsilon_{a}^{+}(t)= \begin{cases}0, & \text { if } t \leq a, \\ 1, & \text { if } t>a .\end{cases}
$$

Definition 1.2. A triangle function is a binary operation on $\Delta^{+}$, namely a function $\tau: \Delta^{+} \times \Delta^{+} \rightarrow \Delta^{+}$that is associative, commutative, non-decreasing in each place and has $\varepsilon_{0}$ as identity, that is, for all $F, G$ and $H$ in $\Delta^{+}$:

(TF1) $\tau(\tau(F, G), H)=\tau(F, \tau(G, H))$;

(TF2) $\tau(F, G)=\tau(G, F)$;

(TF3) $F \leq G \Rightarrow \tau(F, H) \leq \tau(G, H)$;

(TF4) $\tau\left(F, \varepsilon_{0}\right)=\tau\left(\varepsilon_{0}, F\right)=F$.

Typical continuous triangle function is

$$
\Pi_{T}(F, G)(x)=T(F(x), G(x)) .
$$

Here $T$ is a continuous t-norm, i.e., a continuous binary operation on $[0,1]$ that is commutative, associative, non-decreasing in each variable and has 1 as identity; For example

$$
M(x, y)=\min (x, y)
$$

for all $x, y$ in $[0,1]$, is a continuous and maximal t-norm, namely for any t-norm $T, M \geq T$.

Also, note that $\Pi_{M}$ is a maximal triangle function, that is, for every triangle function $\tau, \Pi_{M} \geq \tau$.

Definition 1.3. A Šerstnev Probabilistic Normed space (briefly, Šerstnev PN space) is a triple $(X, \nu, \tau)$, where $X$ is a real vector space, $\tau$ is a continuous triangle function and $\nu$ is a mapping (the probabilistic norm) from $X$ into $\Delta^{+}$, such that for every choice of $p$ and $q$ in $X$ and $a$ in $\mathbb{R}^{+}$, the following hold:

(N1) $\nu(p)=\varepsilon_{0}$, if and only if, $p=\theta \quad(\theta$ is the null vector in $X)$;

(N2) $\nu(a p)(t)=\nu(p)(t /|a|)$;

(N3) $\nu(p+q) \geq \tau(\nu(p), \nu(q))$; 
Let $(X, \nu, \tau)$ be a PN space let $\left\{x_{n}\right\}$ be a sequence in $X$. Then $\left\{x_{n}\right\}$ is said to be convergent if there exists $x \in X$ such that

$$
\lim _{n \rightarrow \infty} \nu\left(x_{n}-x\right)(t)=1
$$

for all $t>0$. In this case $x$ is called the limit of $\left\{x_{n}\right\}$.

The sequence $x_{n}$ in $(X, \nu, \tau)$ is called Cauchy if for each $\varepsilon>0$ and $\delta>0$, there exist some $n_{0}$ such that $\nu\left(x_{n}-x_{m}\right)(\delta)>1-\varepsilon$ for all $m, n \geq n_{0}$.

Clearly, every convergent sequence in a PN space is Cauchy. If each Cauchy sequence is convergent in a $\mathrm{PN}$ space $(X, \nu, \tau)$, then $(X, \nu, \tau)$ is called Probabilistic Banach space (briefly, PB space).

\section{Approximation of quintic mappings on the $\mathrm{PN}$ spaces}

In this section, we investigate the stability problem for system of functional equations (1.9) on the PN spaces.

Theorem 2.1. Let $s \in\{-1,1\}$ be fixed. Let $G$ be a r-divisible group and $\left(Y, \nu, \Pi_{T}\right)$ be a Šerstnev $P B$ space. Let $\phi, \psi: G \times G \times G \rightarrow D^{+}$be functions such that

(2.1)

$$
\begin{aligned}
& \left\{\begin{array}{l}
\phi_{n}^{s}(x, 0, y)(t):=\left\{\phi\left(a^{s n-\left(\frac{1+s}{2}\right)} x, 0, a^{s n-\left(\frac{1+s}{2}\right)} y\right)\left(2 a^{5 s n-\left(\frac{5 s+1}{2}\right)} t\right)\right\}, \quad n=1,2, \ldots \\
\psi_{n}^{s}(x, y, 0)(t):=\left\{\psi\left(a^{s n+\left(\frac{1-s}{2}\right)} x, a^{s n-\left(\frac{1+s}{2}\right)} y, 0\right)\left(2 a^{5 s n+\left(\frac{5-5 s}{2}\right)} t\right)\right\}, n=1,2, \ldots
\end{array}\right. \\
& \left\{\begin{array}{l}
\Phi_{1}:=\Pi_{T}\left\{\phi_{1}^{s}(x, 0, y)(t), \psi_{1}^{s}(x, y, 0)(t)\right\} \\
\Phi_{n}:=\Pi_{T}\left\{\Pi_{T}\left\{\phi_{n}^{s}(x, 0, y)(t), \psi_{n}^{s}(x, y, 0)(t)\right\}, \Phi_{n-1}\right\} \quad \text { for } \quad n>1
\end{array}\right.
\end{aligned}
$$

for all $x, y \in G$ and

$$
\lim _{n \rightarrow \infty} \phi\left(a^{s n} x_{1}, a^{s n} x_{2}, a^{s n} y\right)\left(a^{-5 s n} t\right)=\lim _{n \rightarrow \infty} \psi\left(a^{s n} x, a^{s n} y_{1}, a^{s n} y_{2}\right)\left(a^{-5 s n} t\right)=1
$$

for all $x, y, x_{1}, x_{2}, y_{1}, y_{2} \in G$. Let $\hat{\Phi}=\lim _{n \rightarrow \infty} \Phi_{n}=1$. If $f: G \times G \rightarrow Y$ is a function such that $f(0, y)=0$ for all $y \in G$, and that

$$
\begin{aligned}
& \nu\left(f\left(a x_{1}+b x_{2}, y\right)+f\left(a x_{1}-b x_{2}, y\right)-2 a^{2} f\left(x_{1}, y\right)-2 b^{2} f\left(x_{2}, y\right)\right)(t) \\
\geq & \phi\left(x_{1}, x_{2}, y\right)(t),
\end{aligned}
$$

$$
\begin{aligned}
& \nu\left(f\left(x, a y_{1}+b y_{2}\right)+f\left(x, a y_{1}-b y_{2}\right)-a b^{2} f\left(x, y_{1}+y_{2}\right)-a b^{2} f\left(x, y_{1}-y_{2}\right)\right. \\
& \left.-2 a\left(a^{2}-b^{2}\right) f\left(x, y_{1}\right)\right)(t) \geq \psi\left(x, y_{1}, y_{2}\right)(t)
\end{aligned}
$$

for all $x, y, x_{1}, x_{2}, y_{1}, y_{2} \in G$, then there exists a unique quintic function $T$ : $G \times G \rightarrow Y$ satisfying (1.9) and

$$
\nu(f(x, y)-T(x, y))(t) \geq \hat{\Phi}
$$

for all $x, y \in G$. 
Proof. Putting $x_{1}=2 x$ and $x_{2}=0$ and replacing $y$ by $2 y$ in (2.3), we get

$$
\nu\left(f(2 a x, 2 y)-a^{2} f(2 x, 2 y)\right)(t) \geq \phi(2 x, 0,2 y)(2 t)
$$

for all $x, y \in G$. Putting $y_{1}=2 y$ and $y_{2}=0$ and replacing $x$ by $2 a x$ in (2.4), we get

$$
\nu\left(f(2 a x, 2 a y)-a^{3} f(2 a x, 2 y)\right)(t) \geq \psi(2 a x, 2 y, 0)(2 t)
$$

for all $x, y \in G$. Thus

$$
\nu\left(f(2 a x, 2 a y)-a^{5} f(2 x, 2 y)\right)(t) \geq \Pi_{T}\left\{\phi(2 x, 0,2 y)\left(2 a^{-3} t\right), \psi(2 a x, 2 y, 0)(2 t)\right\}
$$

for all $x, y \in G$. Replacing $x, y$ by $\frac{x}{2}, \frac{y}{2}$ in (2.8), we have

$$
\nu\left(f(a x, a y)-a^{5} f(x, y)\right)(t) \geq \Pi_{T}\left\{\phi(x, 0, y)\left(2 a^{-3} t\right), \psi(a x, y, 0)(2 t)\right\}
$$

for all $x, y \in G$. It follows from (2.9) that

$$
\nu\left(a^{-5} f(a x, a y)-f(x, y)\right)(t) \geq \Pi_{T}\left\{\phi(x, 0, y)\left(2 a^{2} t\right), \psi(a x, y, 0)\left(2 a^{5} t\right)\right\}
$$

and

$$
\begin{aligned}
& \nu\left(a^{5} f\left(a^{-1} x, a^{-1} y\right)-f(x, y)\right)(t) \\
\geq & \Pi_{T}\left\{\phi\left(a^{-1} x, 0, a^{-1} y\right)\left(2 a^{-3} t\right), \psi\left(a x, a^{-1} y, 0\right)(2 t)\right\}
\end{aligned}
$$

for all $x, y \in G$. From the inequalities (2.10) and (2.11) we use iterative methods and induction on $n$ and apply defined sequence in (2.1) to prove our next relation

$$
\begin{aligned}
& \nu\left(a^{-5 s n} f\left(a^{s n} x, a^{s n} y\right)-f(x, y)\right)(t) \\
\geq & \Pi_{T}\left\{\Pi_{T}\left\{\phi_{n}^{s}(x, 0, y)(t), \psi_{n}^{s}(x, y, 0)(t)\right\}, \Phi_{n-1}\right\}
\end{aligned}
$$

for $n=1,2, \ldots$ and all $x, y \in G$. So

$$
\begin{aligned}
& \nu\left(a^{-5 s(n+m)} f\left(a^{s(n+m)} x, a^{s(n+m)} y\right)-f\left(a^{s m} x, a^{s m} y\right)\right)(t) \\
\geq & \Pi_{T}\left\{\Pi_{T}\left\{\phi_{n+m}^{s}(x, 0, y)(t), \psi_{n+m}^{s}(x, y, 0)(t)\right\}, \Phi_{(n+m)-1}\right\}
\end{aligned}
$$

for all nonnegative integers $n$ and $m$ and for all $x, y \in G$. By the assumptions, (2.13) shows that the sequence $\left\{a^{-5 s n} f\left(a^{s n} x, a^{s n} y\right)\right\}$ is a Cauchy sequence in $Y$ for all $x, y \in G$. Since $Y$ is a Banach space, it follows that the sequence $\left\{a^{-5 s n} f\left(a^{s n} x, a^{s n} y\right)\right\}$ converges for all $x, y \in G$. We define the function $T$ : $G \times G \rightarrow Y$ by

$$
T(x, y)=\lim _{n \rightarrow \infty} a^{-5 s n} f\left(a^{s n} x, a^{s n} y\right)
$$

for all $x, y \in G$. It follows from (2.3) that

$$
\begin{aligned}
& \nu\left(T\left(a x_{1}+b x_{2}, y\right)+T\left(a x_{1}-b x_{2}, y\right)-2 a^{2} T\left(x_{1}, y\right)-2 b^{2} T\left(x_{2}, y\right)\right)(t) \\
= & \lim _{n \rightarrow \infty} \nu\left(a^{-5 s n} f\left(a^{s n}\left(a x_{1}+b x_{2}\right), a^{s n} y\right)+a^{-5 s n} f\left(a^{s n}\left(a x_{1}-b x_{2}\right), a^{s n} y\right)\right. \\
& \left.-2 a^{-5 s n} a^{2} f\left(a^{s n} x_{1}, a^{s n} y\right)-2 a^{-5 s n} b^{2} f\left(a^{s n} x_{2}, a^{s n} y\right)\right)(t) \\
\geq & \lim _{n \rightarrow \infty} \phi\left(a^{s n} x_{1}, a^{s n} x_{2}, a^{s n} y\right)\left(a^{-5 s n} t\right)=1
\end{aligned}
$$


for all $x_{1}, x_{2}, y \in G$. Also it follows from (2.4) that

$$
\begin{aligned}
& \nu\left(T\left(x, a y_{1}+b y_{2}\right)+T\left(x, a y_{1}-b y_{2}\right)-a b^{2}\left(T\left(x, y_{1}+y_{2}\right)\right.\right. \\
& \left.\left.-T\left(x, y_{1}-y_{2}\right)\right)-2 a\left(a^{2}-b^{2}\right) T\left(x, y_{1}\right)\right)(t) \\
= & \lim _{n \rightarrow \infty} \nu\left(a^{-5 s n} f\left(a^{s n} x, a^{s n}\left(a y_{1}+b y_{2}\right)\right)+a^{-5 s n} f\left(a^{s n} x, a^{s n}\left(a y_{1}-b y_{2}\right)\right)\right. \\
& -a^{-5 s n} a b^{2} f\left(a^{s n} x, a^{s n}\left(y_{1}+y_{2}\right)\right)-a^{-5 s n} a b^{2} f\left(a^{s n} x, a^{s n}\left(y_{1}-y_{2}\right)\right) \\
& \left.-2 a^{-5 s n} a\left(a^{2}-b^{2}\right) f\left(a^{s n} x, a^{s n} y_{1}\right)\right)(t) \\
\geq & \lim _{n \rightarrow \infty} a^{-5 s n} \psi\left(a^{s n} x, a^{s n} y_{1}, a^{s n} y_{2}\right)(t)=1
\end{aligned}
$$

for all $x, y_{1}, y_{2} \in G$. This means that $T$ satisfies (1.9) that is, $T$ is quintic. Moreover, passing the limit $n \rightarrow \infty$ in (2.12), we get the inequality (2.5).

Now, let $T^{\prime}: G \times G \rightarrow Y$ be another quintic function satisfying (1.9) and (2.5). By Proposition 1.1 we have $a^{-5 s n} T^{\prime}\left(a^{s n} x, a^{s n} y\right)=T^{\prime}(x, y)$ for all $x, y \in$ $G$. Therefore we conclude that

$$
\begin{aligned}
& \nu\left(T(x, y), T^{\prime}(x, y)\right)(t) \\
= & \lim _{n \rightarrow \infty} \nu\left(a^{-5 s n} T\left(a^{s n} x, a^{s n} y\right)-a^{-5 s n} T^{\prime}\left(a^{s n} x, a^{s n} y\right)\right)(t) \\
\geq & \lim _{n \rightarrow \infty} \Pi_{T}\left\{\Pi_{T}\left\{\phi_{n}^{s}\left(a^{s n} x, 0, a^{s n} y\right)\left(a^{-5 s n} t\right), \psi_{n}^{s}\left(a^{s n} x, a^{s n} y, 0\right)\left(a^{-5 s n} t\right)\right\}, \Phi_{n-1}\right\}
\end{aligned}
$$

which tends to 1 as $n \rightarrow \infty$ for all $x, y \in G$. So we can conclude that $T(x, y)=$ $T^{\prime}(x, y)$ for all $x, y \in G$. This proves the uniqueness of $T$.

\section{Approximation of sextic mappings on the PN spaces}

In this section, we investigate the stability problem for system of functional equations (1.10) on the PN spaces.

Theorem 3.1. Let $s \in\{-1,1\}$ be fixed. Let $G$ be a $r$-divisible group and $\left(Y, \nu, \Pi_{T}\right)$ be a Šerstnev $P B$ space. Let $\Phi, \Psi, \Upsilon: G \times G \times G \rightarrow[0, \infty)$ be functions such that

$$
\begin{aligned}
& \left\{\begin{array}{l}
\Phi_{n}^{s}(x, 0, y, z)(t):=\left\{\Phi\left(a^{-s n+\frac{3 s-1}{2}} x, 0, a^{-s n+\frac{3 s-1}{2}} y, a^{-s n+\frac{3 s-1}{2}} z\right)\left(2 a^{(9 s+8)-6 s n} t\right)\right\}, \\
\Psi_{n}^{s}(x, y, 0, z)(t):=\left\{\Psi\left(a^{-s n+\frac{3 s+1}{2}} x, a^{-s n+\frac{3 s-1}{2}} y, 0, a^{-s n+\frac{3 s-1}{2}} z\right)\left(2 a^{(9 s+6)-6 s n} t\right)\right\}, \\
\Upsilon_{n}^{s}(x, y, z, 0)(t):=\left\{\Upsilon\left(a^{-s n+\frac{3 s+1}{2}} x, a^{-s n+\frac{3 s+1}{2}} y, a^{-s n+\frac{3 s-1}{2}} z, 0\right)\left(2 a^{(9 s+3)-6 s n} t\right)\right\},
\end{array}\right. \\
& n=1,2, \ldots, \\
& \left\{\begin{array}{l}
\Theta_{1}:=\Pi_{T}\left\{\Upsilon_{1}^{s}(x, y, z, 0)(t), \Pi_{T}\left\{\Psi_{1}^{s}(x, y, 0, z)(t), \Phi_{1}^{s}(x, 0, y, z)(t)\right\}\right\} \\
\Theta_{n}:=\Pi_{T}\left\{\Pi_{T}\left\{\Upsilon_{n}^{s}(x, y, z, 0)(t), \Pi_{T}\left\{\Psi_{n}^{s}(x, y, 0, z)(t), \Phi_{n}^{s}(x, 0, y, z)(t)\right\}\right\}, \Theta_{n-1}\right\}
\end{array}\right. \\
& \quad \text { for } \quad n>1,
\end{aligned}
$$


for all $x, y, z \in G$ and

$$
\begin{aligned}
& \lim _{n \rightarrow \infty} \Phi\left(a^{s n} x_{1}, a^{s n} x_{2}, a^{s n} y, a^{s n} z\right)\left(a^{-6 s n} t\right) \\
= & \lim _{n \rightarrow \infty} \Psi\left(a^{s n} x, a^{s n} y_{1}, a^{s n} y_{2}, a^{s n} z\right)\left(a^{-6 s n} t\right) \\
= & \lim _{n \rightarrow \infty} \Upsilon\left(a^{s n} x, a^{s n} y, a^{s n} z_{1}, a^{s n} z_{2}\right)\left(a^{-6 s n} t\right)=1
\end{aligned}
$$

for all $x, y, x_{1}, x_{2}, y_{1}, y_{2}, z_{1}, z_{2} \in G$. Let $\hat{\Theta}=\lim _{n \rightarrow \infty} \Theta_{n}=1$. If $f: G \times G \times$ $G \rightarrow Y$ is a function such that $f(x, 0, z)=0$ for all $x, z \in G$ and that

$$
\begin{aligned}
& \nu\left(f\left(a x_{1}+b x_{2}, y, z\right)+f\left(a x_{1}-b x_{2}, y, z\right)-2 a f\left(x_{1}, y, z\right)\right)(t) \\
\geq & \Phi\left(x_{1}, x_{2}, y, z\right)(t),
\end{aligned}
$$

$$
\nu\left(f\left(x, a y_{1}+b y_{2}, z\right)+f\left(x, a y_{1}-b y_{2}, z\right)-2 a^{2} f\left(x, y_{1}, z\right)-2 b^{2} f\left(x, y_{2}, z\right)\right)(t)
$$

$\geq \Psi\left(x, y_{1}, y_{2}, z\right)(t)$,

$$
\begin{aligned}
& \nu\left(f\left(x, y, a z_{1}+b z_{2}\right)+f\left(x, y, a z_{1}-b z_{2}\right)-a b^{2}\left(f\left(x, y, z_{1}+z_{2}\right)+f\left(x, y, z_{1}-z_{2}\right)\right)\right. \\
& \left.-2 a\left(a^{2}-b^{2}\right) f\left(x, y, z_{1}\right)\right)(t) \geq \Upsilon\left(x, y, z_{1}, z_{2}\right)(t)
\end{aligned}
$$

for all $x, y, x_{1}, x_{2}, y_{1}, y_{2}, z_{1}, z_{2} \in G$, then there exists a unique quintic function $T: G \times G \times G \rightarrow Y$ satisfying (1.9) and

$$
\nu(f(x, y, z)-T(x, y, z))(t) \geq \hat{\Theta}
$$

for all $x, y, z \in G$.

Proof. Putting $x_{1}=2 x$ and $x_{2}=0$ and replacing $y, z$ by $2 y, 2 z$ in (3.3), we get

$$
\nu(f(2 a x, 2 y, 2 z)-a f(2 x, 2 y, 2 z))\left(\frac{1}{2} t\right) \geq \Phi(2 x, 0,2 y, 2 z)(t)
$$

for all $x, y, z \in G$. Putting $y_{1}=2 y$ and $y_{2}=0$ and replacing $x, z$ by $2 a x, 2 z$ in (3.4), we get

$$
\nu\left(f(2 a x, 2 a y, 2 z)-a^{2} f(2 a x, 2 y, 2 z)\right)\left(\frac{1}{2} t\right) \geq \Psi(2 a x, 2 y, 0,2 z)(t)
$$

for all $x, y, z \in G$. Putting $z_{1}=2 z$ and $z_{2}=0$ and replacing $x, y$ by $2 a x, 2 a y$ in (3.5), we get

$$
\nu\left(f(2 a x, 2 a y, 2 a z)-a^{3} f(2 a x, 2 a y, 2 z)\right)\left(\frac{1}{2} t\right) \geq \Upsilon(2 a x, 2 a y, 2 z, 0)(t)
$$

for all $x, y, z \in G$. Thus

(3.10)

$$
\nu\left(f(2 a x, 2 a y, 2 a z)-a^{6} f(2 x, 2 y, 2 z)\right)(t)
$$

$\geq \Pi_{T}\left\{\Upsilon(2 a x, 2 a y, 2 z, 0)(2 t), \Pi_{T}\left\{\Psi(2 a x, 2 y, 0,2 z)\left(2 a^{3} t\right), \Phi(2 x, 0,2 y, 2 z)\left(2 a^{5} t\right)\right\}\right\}$ 
for all $x, y, z \in G$. Replacing $x, y$ and $z$ by $\frac{x}{2}, \frac{y}{2}$ and $\frac{z}{2}$ in (3.10), we have

$$
\begin{aligned}
& \nu\left(f(a x, a y, a z)-a^{6} f(x, y, z)\right)(t) \\
\geq & \Pi_{T}\left\{\Upsilon(a x, a y, z, 0)(2 t), \Pi_{T}\left\{\Psi(a x, y, 0, z)\left(2 a^{3} t\right), \Phi(x, 0, y, z)\left(2 a^{5} t\right)\right\}\right\}
\end{aligned}
$$

for all $x, y, z \in G$. It follows from (3.11) that

$$
\begin{aligned}
& \nu\left(a^{-6} f(a x, a y, a z)-f(x, y, z)\right)(t) \\
\geq & \Pi_{T}\left\{\Upsilon(a x, a y, z, 0)\left(2 a^{6} t\right), \Pi_{T}\left\{\Psi(a x, y, 0, z)\left(2 a^{9} t\right), \Phi(x, 0, y, z)\left(2 a^{11} t\right)\right\}\right\}
\end{aligned}
$$

and

$$
\begin{aligned}
& \nu\left(a^{6} f\left(a^{-1} x, a^{-1} y, a^{-1} z\right)-f(x, y, z)\right)(t) \\
\geq & \Pi_{T}\left\{\Upsilon\left(x, y, a^{-1} z, 0\right)(2 a t), \Pi_{T}\left\{\Psi\left(x, a^{-1} y, 0, a^{-1} z\right)\left(2 a^{3} t\right), \Phi\left(a^{-1} x, 0, a^{-1} y, a^{-1} z\right)\left(2 a^{5} t\right)\right\}\right\}
\end{aligned}
$$

for all $x, y, z \in G$. From the inequalities (3.12) and (3.13) we use iterative methods and induction on $n$ and apply defined sequence in (3.1) to prove our next relation

$$
\begin{aligned}
& \nu\left(a^{-6 s n} f\left(a^{s n} x, a^{s n} y, a^{s n} z\right)-f(x, y, z)\right)(t) \\
\geq & \Pi_{T}\left\{\Pi_{T}\left\{\Upsilon_{n}^{s}(x, y,, z, 0)(t), \Pi_{T}\left\{\Phi_{n}^{s}(x, 0, y, z)(t), \Psi_{n}^{s}(x, y, 0, z)(t)\right\}\right\}, \Theta_{n-1}\right\}
\end{aligned}
$$

for all $x, y, z \in G$. So

$$
\begin{aligned}
& \nu\left(a^{-6 s(n+m)} f\left(a^{s(n+m)} x, a^{s(n+m)} y, a^{s(n+m)} z\right)-f\left(a^{s m} x, a^{s m} y, a^{s m} z\right)\right)(t) \\
\geq & \Pi_{T}\left\{\Pi_{T}\left\{\Upsilon_{n+m}^{s}(x, y, z, 0)(t), \Pi_{T}\left\{\Phi_{n+m}^{s}(x, 0, y, z)(t), \Psi_{n+m}^{s}(x, y, 0, z)(t)\right\}\right\}, \Theta_{(n+m)-1}\right\}
\end{aligned}
$$

for all nonnegative integers $n$ and $m$ and for all $x, y, z \in G$. By the assumptions, (3.15) shows that the sequence $\left\{a^{-6 s n} f\left(a^{s n} x, a^{s n} y, a^{s n} z\right)\right\}$ is a Cauchy sequence in $Y$ for all $x, y, z \in G$. Since $Y$ is a Banach space, it follows that the sequence $\left\{a^{-6 s n} f\left(a^{s n} x, a^{s n} y, a^{s n} z\right)\right\}$ converges for all $x, y, z \in G$. We define the function $T: G \times G \times G \rightarrow Y$ by

$$
T(x, y, z)=\lim _{n \rightarrow \infty} a^{-6 s n} f\left(a^{s n} x, a^{s n} y, a^{s n} z\right)
$$

for all $x, y, z \in G$. It follows from (3.3), (3.4) and (3.5) that

$$
\begin{aligned}
& \nu\left(T\left(a x_{1}+b x_{2}, y, z\right)+T\left(a x_{1}-b x_{2}, y, z\right)-2 a T\left(x_{1}, y, z\right)\right)(t) \\
= & \lim _{n \rightarrow \infty} \nu\left(a^{-6 s n} f\left(a^{s n}\left(a x_{1}+b x_{2}\right), a^{s n} y, a^{s n} z\right)+a^{-6 s n} f\left(a^{s n}\left(a x_{1}-b x_{2}\right),\right.\right. \\
& \left.\left.a^{s n} y, a^{s n} z\right)-2 a a^{-6 s n} f\left(a^{s n} x_{1}, a^{s n} y, a^{s n} z\right)\right)(t) \\
\geq & \lim _{n \rightarrow \infty} \Phi\left(a^{s n} x_{1}, a^{s n} x_{2}, a^{s n} y, a^{s n} z\right)\left(a^{-6 s n} t\right)=1,
\end{aligned}
$$


(3.18)

$$
\begin{aligned}
& \nu\left(T\left(x, a y_{1}+b y_{2}, z\right)+T\left(x, a y_{1}-b y_{2}, z\right)-2 a^{2} T\left(x, y_{1}, z\right)-2 b^{2} T\left(x, y_{2}, z\right)\right)(t) \\
= & \lim _{n \rightarrow \infty} \nu\left(a^{-6 s n} f\left(a^{s n} x, a^{s n}\left(a y_{1}+b y_{2}\right), a^{s n} z\right)+f\left(a^{s n} x, a^{s n} a y_{1}-a^{s n} b y_{2}, a^{s n} z\right)\right. \\
& \left.-2 a^{2} a^{-6 s n} f\left(a^{s n} x, a^{s n} y_{1}, a^{s n} z\right)+2 b^{2} a^{-6 s n} f\left(a^{s n} x, a^{s n} y_{2}, a^{s n} z\right)\right)(t) \\
\geq & \lim _{n \rightarrow \infty} \Psi\left(a^{s n} x, a^{s n} y_{1}, a^{s n} y_{2}, a^{s n} z\right)\left(a^{-6 s n} t\right)=1,
\end{aligned}
$$

$$
\begin{aligned}
& \nu\left(T\left(x, y, a z_{1}+b z_{2}\right)+T\left(x, y, a z_{1}-b z_{2}\right)-a b^{2}\left(T\left(x, y, z_{1}+z_{2}\right)\right.\right. \\
& \left.\left.-T\left(x, y, z_{1}-z_{2}\right)\right)-2 a\left(a^{2}-b^{2}\right) T\left(x, y, z_{1}\right)\right)(t) \\
= & \lim _{n \rightarrow \infty} \nu\left(a^{-6 s n} f\left(a^{s n} x, a^{s n} y, a^{s n}\left(a z_{1}+b z_{2}\right)\right)+a^{-6 s n} f\left(a^{s n} x, a^{s n} y, a^{s n}\left(a z_{1}-b z_{2}\right)\right)\right. \\
& -a b^{2} a^{-6 s n}\left(f\left(a^{s n} x, a^{s n} y, a^{s n}\left(z_{1}+z_{2}\right)\right)+f\left(a^{s n} x, a^{s n} y, a^{s n}\left(z_{1}-z_{2}\right)\right)\right) \\
& \left.-2 a a^{-6 s n}\left(a^{2}-b^{2}\right) f\left(a^{s n} x, a^{s n} y, a^{s n} z_{1}\right)\right)(t) \\
\geq & \lim _{n \rightarrow \infty} \Upsilon\left(a^{s n} x, a^{s n} y, a^{s n} z_{1}, a^{s n} z_{2}\right)\left(a^{-6 s n} t\right)=1
\end{aligned}
$$

for all $x, y, x_{1}, x_{2}, y_{1}, y_{2}, z_{1}, z_{2} \in G$. This means that $T$ satisfies (1.10), that is, $T$ is sextic. Moreover, passing the limit $n \rightarrow \infty$ in (3.15), we get the inequality (3.6). Now, let $T^{\prime}: G \times G \times G \rightarrow Y$ be another sextic function satisfying (1.10) and (3.6). By Proposition 1.2 we have $a^{-6 s n} T^{\prime}\left(a^{s n} x, a^{s n} y, a^{s n} z\right)=T^{\prime}(x, y, z)$ for all $x, y, z \in G$. Therefore we conclude that

$$
\begin{aligned}
& \nu\left(T(x, y, z), T^{\prime}(x, y, z)\right)(t) \\
= & \lim _{n \rightarrow \infty} \nu\left(a^{-6 s n} f\left(a^{s n} x, a^{s n} y, a^{s n} z\right)-a^{-6 s n} T^{\prime}\left(a^{s n} x, a^{s n} y, a^{s n} z\right)\right)(t) \\
\geq & \lim _{n \rightarrow \infty} \Pi_{T}\left\{\Pi _ { T } \left\{\Upsilon_{n}^{s}\left(a^{s n} x, a^{s n} y, a^{s n} z, 0\right)\left(a^{-6 s n} t\right), \Pi_{T}\left\{\Phi_{n}^{s}\left(a^{s n} x, 0, a^{s n} y, a^{s n} z\right)\right.\right.\right. \\
& \left.\left.\left.\left(a^{-6 s n} t\right), \Psi_{n}^{s}\left(a^{s n} x, a^{s n} y, 0, a^{s n} z\right)\left(a^{-6 s n} t\right)\right\}\right\}, \Theta_{n-1}\right\}
\end{aligned}
$$

which tends to 1 as $n \rightarrow \infty$ for all $x, y \in G$. So we can conclude that $T(x, y, z)=$ $T^{\prime}(x, y, z)$ for all $x, y, z \in G$. This proves the uniqueness of $T$.

\section{References}

[1] J. Aczel and J. Dhombres, Functional Equations in Several Variables, Cambridge University Press, Cambridge, 1989.

[2] C. Alsina, B. Schweizer, and A. Sklar, On the definition of a probabilistic normed space, Aequationes Math. 46 (1993), no. 1-2, 91-98.

[3] T. Aoki, On the stability of the linear transformation in Banach spaces, J. Math. Soc. Japan 2 (1950), 64-66.

[4] P. W. Cholewa, Remarks on the stability of functional equations, Aequationes Math. 27 (1984), no. 1-2, 76-86.

[5] J. K. Chung and P. K. Sahoo, On the general solution of a quartic functional equation, Bull. Korean Math. Soc. 40 (2003), no. 4, 565-576.

[6] S. Czerwik, On the stability of the quadratic mapping in normed spaces, Abh. Math. Sem. Univ. Hamburg 62 (1992), 59-64. 
[7] _ Functional Equations and Inequalities in Several Variables, World Scientific, London, 2002.

[8] A. Ebadian, N. Ghobadipour, and M. E. Gordji, A fixed point method for perturbation of bimultipliers and Jordan bimultipliers in $C^{*}$-ternary algebras, J. Math. Phys. 51 (2010), no. 1, 10 pages, doi:10.1063/1.3496391.

[9] A. Ebadian, A. Najati, and M. Eshaghi Gordji, On approximate additive-quartic and quadratic-cubic functional equations in two variables on abelian groups, Results Math. 58 (2010), no. 1-2, 39-53.

[10] M. Eshaghi Gordji, Stability of a functional equation deriving from quartic and additive functions, Bull. Korean Math. Soc. 47 (2010), no. 3, 491-502.

[11] _ Stability of an additive-quadratic functional equation of two variables in Fspaces, J. Nonlinear Sci. Appl. 2 (2009), no. 4, 251-259.

[12] M. Eshaghi Gordji, S. Abbaszadeh, and C. Park, On the stability of generalized mixed type quadratic and quartic functional equation in quasi-Banach spaces, J. Ineq. Appl. 2009 (2009), Article ID 153084, 26 pages.

[13] M. Eshaghi Gordji and M. Bavand-Savadkouhi, On approximate cubic homomorphisms, Adv. Difference Equ. 2009 (2009), Art. ID 618463, 11 pp., doi:10.1155/2009/618463.

[14] M. Eshaghi Gordji, S. Zolfaghari, J. M. Rassias, and M. B. Savadkouhi, Solution and stability of a mixed type cubic and quartic functional equation in quasi-Banach spaces, Abstr. Appl. Anal. 2009 (2009), Art. ID 417473, 1-14.

[15] M. Eshaghi Gordji, A. Ebadian, and S. Zolfaghari, Stability of a functional equation deriving from cubic and quartic functions, Abs. Appl. Anal. 2008 (2008), Article ID 801904, 17 pages.

[16] M. Eshaghi Gordji, M. B. Ghaemi, S. Kaboli Gharetapeh, S. Shams, and A. Ebadian, On the stability of $J^{*}$-derivations, J. Geom. Phys. 60 (2010), no. 3, 454-459.

[17] M. Eshaghi Gordji, M. B. Ghaemi, and H. Majani, Generalized Hyers-Ulam-Rassias Theorem in Menger Probabilistic Normed Spaces, Discrete Dyn. Nat. Soc. 2010 (2010), Art. ID 162371, 11 pp.

[18] M. Eshaghi Gordji, M. B. Ghaemi, H. Majani, and C. Park, Generalized Ulam-Hyers stability of Jensen functional equation in Sherstnev PN spaces, J. Inequal. Appl. 2010 (2010), Art. ID 868193, 14 pp.

[19] M. Eshaghi Gordji and N. Ghobadipour, Stability of $(\alpha, \beta, \gamma)$-derivations on Lie $C^{*}$-algebras, Int. J. Geom. Methods Mod. Phys. 7 (2010), no. 7, 1093-1102.

[20] M. Eshaghi Gordji, S. Kaboli Gharetapeh, T. Karimi, E. Rashidi, and M. Aghaei, Ternary Jordan $*$-derivations in $C^{*}$-ternary algebras, J. Comput. Anal. Appl. 12 (2010), no. 2, 463-470.

[21] M. Eshaghi Gordji, S. Kaboli-Gharetapeh, C. Park, and S. Zolfaghri, Stability of an additive-cubic-quartic functional equation, Adv. Difference Equ. 2009 (2009), Article ID 395693, 20 pages.

[22] M. Eshaghi Gordji, S. Kaboli Gharetapeh, J. M. Rassias, and S. Zolfaghari, Solution and stability of a mixed type additive, quadratic and cubic functional equation, Adv. Difference Equ. 2009 (2009), Article ID 826130, 17 pages.

[23] M. Eshaghi Gordji, T. Karimi, and S. Kaboli Gharetapeh, Approximately n-Jordan homomorphisms on Banach algebras, J. Inequal. Appl. 2009 (2009), Article ID 870843, 8 pages.

[24] M. Eshaghi Gordji and H. Khodaei, Solution and stability of generalized mixed type cubic, quadratic and additive functional equation in quasi-Banach spaces, Nonlinear Anal. 71 (2009), no. 11, 5629-5643.

[25] - On the generalized Hyers-Ulam-Rassias stability of quadratic functional equations, Abstr. Appl. Anal. 2009 (2009), Article ID 923476, 11 pages. 
[26] M. Eshaghi Gordji and H. Khodaei, The fixed point method for fuzzy approximation of a functional equation associated with inner product spaces, Discrete Dyn. Nat. Soc. 2010 (2010), Article ID 140767, 15 pages, doi:10.1155/2010/140767.

[27] M. Eshaghi Gordji, H. Khodaei, and R. Khodabakhsh, General quartic-cubic-quadratic functional equation in non-Archimedean normed spaces, Politehn. Univ. Bucharest Sci. Bull. Ser. A Appl. Math. Phys. 72 (2010), no. 3, 69-84.

[28] M. Eshaghi Gordji and A. Najati, Approximately $J^{*}$-homomorphisms: A fixed point approach, J. Geom. Phys. 60 (2010), no. 5, 809-814.

[29] M. Eshaghi Gordji, J. M. Rassias, and N. Ghobadipour, Generalized Hyers-Ulam stability of the generalized ( $n, k)$-derivations, Abstr. Appl. Anal. 2009 (2009), Article ID 437931, 8 pages.

[30] M. Eshaghi Gordji and M. B. Savadkouhi, Approximation of generalized homomorphisms in quasi-Banach algebras, Analele Univ. Ovidius Constata, Math series 17 (2009), no. 2, 203-214.

[31] Stability of cubic and quartic functional equations in non-Archimedean spaces, Acta Appl. Math. 110 (2010), no. 3, 1321-1329.

[32] _ Stability of mixed type cubic and quartic functional equations in random normed spaces, J. Inequal. Appl. 2009 (2009), Article ID 527462, 9 pages.

[33] Stability of a mixed type cubic-quartic functional equation in non-Archimedean spaces, Appl. Math. Lett. 23 (2010), no. 10, 1198-1202.

[34] M. Eshaghi Gordji, M. B. Savadkouhim, and M. Bidkham, Stability of a mixed type additive and quadratic functional equation in non-Archimedean spaces, J. Comput. Anal. Appl. 12 (2010), no. 2, 454-462.

[35] M. Eshaghi Gordji, M. B. Savadkouhi, and C. Park, Quadratic-quartic functional equations in RN-spaces, J. Inequal. Appl. 2009 (2009), Article ID 868423, 14 pages.

[36] Z. Gajda, On stability of additive mappings, Internat. J. Math. Math. Sci. 14 (1991), no. 3, 431-434.

[37] P. Găvruta, A generalization of the Hyers-Ulam-Rassias stability of approximately additive mappings, J. Math. Anal. Appl. 184 (1994), no. 3, 431-436.

[38] P. Găvruta and L. Găvruta, A new method for the generalized Hyers-Ulam-Rassias stability, Int. J. Nonlinear Anal. Appl. 1 (2010), no. 2, 11-18.

[39] N. Ghobadipour, M. Eshaghi gordji, A. Ebadian, and Rassias, A perturbation of double derivations on Banach algebras, Commun. Math. Anal. 11 (2011), no. 1, 51-60.

[40] D. H. Hyers, On the stability of the linear functional equation, Proc. Nat. Acad. Sci. USA 27 (1941), 222-224.

[41] D. H. Hyers, G. Isac, and T. M. Rassias, Stability of Functional Equations in Several Variables, Birkhauser, Basel, 1998.

[42] K. W. Jun and H. M. Kim, The generalized Hyers-Ulam-Rassias stability of a cubic functional equation, J. Math. Anal. Appl. 274 (2002), 267-278.

[43] K. W. Jun, H. M. Kim, and I. S. Chang, On the Hyers-Ulam stability of an EulerLagrange type cubic functional equation, J. Comput. Anal. Appl. 7 (2005), no. 1, 21-33.

[44] S.-M. Jung, Hyers-Ulam-Rassias Stability of Functional Equations in Mathematical Analysis, Hadronic Press Inc., Palm Harbor, Florida, 2001.

[45] _ Hyers-Ulam-Rassias stability of Jensen's equation and its application, Proc. Amer. Math. Soc. 126 (1998), no. 11, 3137-3143.

[46] Stability of the quadratic equation of Pexider type, Abh. Math. Sem. Univ. Hamburg 70 (2000), 175-190.

[47] P. Kannappan, Quadratic functional equation and inner product spaces, Results Math. 27 (1995), no. 3-4, 368-372.

[48] H. Khodaei and M. Kamyar, Fuzzy approximately additive mappings, Int. J. Nonlinear Anal. Appl. 1 (2010), no. 2, 44-53. 
[49] H. Khodaei and Th. M. Rassias, Approximately generalized additive functions in several variables, Int. J. Nonlinear Anal. Appl. 1 (2010), 22-41.

[50] S. H. Lee, S. M. Im, and I. S. Hawng, Quartic functional equation, J. Math. Anal. Appl. 307 (2005), no. 2, 387-394.

[51] A. K. Mirmostafaee, Stability of Quartic Mappings in Non-Archimedean Normed Spaces, Kyungpook Math. J. 49 (2009), 289-297.

[52] A. Najati, On the stability of a quartic functional equation, J. Math. Anal. Appl. 340 (2008), no. 1, 569-574.

[53] - Hyers-Ulam-Rassias stability of a cubic functional equation, Bull. Korean Math. Soc. 44 (2007), no. 4, 825-840.

[54] A. Najati and F. Moradlou, Stability of an Euler-Lagrange type cubic functional equation, Turkish J. Math. 33 (2009), no. 1, 65-73.

[55] Stability of a mixed additive, quadratic and cubic functional equation in quasiBanach spaces, Aust. J. Math. Anal. Appl. 5 (2008), no. 2, 10-21.

[56] A. Najati and G. Zamani Eskandani, Stability of a mixed additive and cubic functional equation in quasi-Banach spaces, J. Math. Anal. Appl. 342 (2008), no. 2, 1318-1331.

[57] A. Najati and C. Park, On the stability of a cubic functional equation, Acta Math. Sin. (Engl. Ser.) 24 (2008) no. 12, 1953-1964.

[58] C. Park, On an approximate automorphism on a $C^{*}$-algebra, Proc. Amer. Math. Soc. 132 (2004), no. 6, 1739-1745.

[59] - On the stability of the orthogonally quartic functional equation, Bull. Iranian Math. Soc. 31 (2005), no. 1, 63-70.

[60] C. Park and M. E. Gordji, Comment on "Approximate ternary Jordan derivations on Banach ternary algebras" [Bavand Savadkouhi et al. J. Math. Phys. 50, 042303 (2009)] [MR2513974], J. Math. Phys. 51 (2010), no. 4, 044102, 7 pp.

[61] C. Park and A. Najati, Generalized additive functional inequalities in Banach algebras, Int. J. Nonlinear Anal. Appl. 1 (2010), no. 2, 54-62.

[62] C. Park and J. M. Rassias, Stability of the Jensen-type functional equation in $C^{*}$ algebras: A Fixed Point Approach, Abstr. Appl. Anal. 2009 (2009), Art. ID 360432, 1-17, Doi:10.1155/2009/360432.

[63] _ Isomorphisms in unital $C^{*}$-algebras, Int. J. Nonlinear Anal. Appl. 1 (2010), no. $2,1-10$.

[64] J. M. Rassias, On approximation of approximately linear mappings by linear mappings, J. Funct. Anal. 46 (1982), no. 1, 126-130.

[65] On Approximation of approximately linear mappings by linear mappings, Bull. Sci. Math. (2) 108 (1984), no. 4, 445-446.

[66] - On a new approximation of approximately linear mappings by linear mappings, Discuss. Math. 7 (1985), 193-196.

[67] _ Solution of a problem of Ulam, J. Approx. Theory 57 (1989), no. 3, 268-273.

[68] _ On the stability of the Euler-Lagrange functional equation, Chinese J. Math. 20 (1992), no. 2, 185-190.

[69] _ Solution of a stability problem of Ulam, Discuss. Math. 12 (1992), 95-103.

[70] _ On the stability of the non-linear Euler-Lagrange functional equation in real normed linear spaces, J. Math. Phys. Sci. 28 (1994), no. 5, 231-235.

[71] _ On the stability of a multi-dimensional Cauchy type functional equation, Geometry, analysis and mechanics, 365-376, World Sci. Publ., River Edge, NJ, 1994.

[72] On the stability of the linear mapping in Banach spaces, Proc. Amer. Math. Soc. 72 (1978), no. 2, 297-300.

[73] _ New characterization of inner product spaces, Bull. Sci. Math. 108 (1984), no. 1, 95-99.

[74] Th. M. Rassias, P. Šemrl, On the behaviour of mappings which do not satisfy HyersUlam stability, Proc. Amer. Math. Soc. 114 (1992), 989-993. 
[75] K. Ravi, M. Arunkumar, and J. M. Rassias, Ulam stability for the orthogonally general Euler-Lagrange type functional equation, Int. J. Math. Stat. 3 (2008), 36-46.

[76] B. Schweizer and A. Sklar, Probabilistic Metric Spaces, Elsevier North Holand, New York, 1983

[77] A. N. Šerstnev, On the motion of a random normed space, Dokl. Akad. Nauk SSSR 149 (1963), 280-283; English translation in Soviet Math. Dokl. 4 (1963), 388-390.

[78] S. Shakeri, R. Saadati, and C. Park, Stability of the quadratic functional equation in non-Archimedean $\mathcal{L}$-fuzzy normed spaces, Int. J. Nonlinear Anal. Appl. 1 (2010), no. 2, 72-83.

[79] F. Skof, Local properties and approximation of operators, Geometry of Banach spaces and related topics (Italian) (Milan, 1983). Rend. Sem. Mat. Fis. Milano 53 (1983), 113129 (1986)

[80] S. M. Ulam, Problems in Modern Mathematics, Chapter VI, Science Editions, Wiley, New York, 1964

Mohammad Bagher Ghaemi

Department of Mathematics

Iran University of Science and Technology

NARmak, Tehran, Iran

E-mail address: mghaemi@iust.ac.ir

HAMid MAJANI

Department of Mathematics

Iran University of Science and Technology

Narmak, Tehran, Iran

E-mail address: majani.hamid@yahoo.com

Majid Eshaghi GoRdjI

Department of Mathematics

Semnan University

P. O. Box 35195-363, Semnan, Iran

Center of Excellence in Nonlinear Analysis and Applications (CEnAA)

SEMnan University

IRAN

E-mail address: madjid.eshaghi@gmail.com 